\title{
Cardiac Surgery without Donor Blood Transfusion at a Referral Cardiac Institute in Bangladesh
}

\author{
Kazi Shariful Islam, SAMA Sabur²,Kazi Abul Hasan³, Begum Marjan Mahal Chowdhury4, \\ Nilufar Yasmin 5 , Mohammad Zahid ${ }^{6}$ \\ ${ }^{1}$ Associate Professor, Department of Cardiac Surgery, National Institute of Cardiovascular Diseases, Dhaka, Bangladesh \\ ${ }^{2}$ Former Associate Professor, Department of Cardiac Surgery, National Institute of Cardiovascular Diseases, Dhaka, \\ Bangladesh; ${ }^{3}$ Former Professor, Department of Paediatric Cardiac Surgery, National Institute of Cardiovascular \\ Diseases, Dhaka, Bangladesh; ${ }^{4}$ Professor, Department of Cardiac Anaesthesia, National Institute of Cardiovascular \\ Diseases, Dhaka, Bangladesh; ${ }^{5}$ Former Perfusionist, National Institute of Cardiovascular Diseases, \\ Dhaka,Bangladesh; ${ }^{6}$ Assistant Registrar, Department of Cardiac Surgery, National Institute of \\ Cardiovascular Diseases, Dhaka, Bangladesh
}

[Received: 12 October 2018; Accepted: 2 November 2018; Published: 1 January 2019]

\begin{abstract}
Background: Blood transfusion is always associated with some hazards despite economic and work burden on laboratory staffs. Pre-donation and blood conservation can help to avoid transfusion related hazards with good posto-perative outcome. Objective: The main objective of this study was to show the varieties of cardiac surgery without donor blood transfusion. Methodology: Patients were selected conveniently. Preoperative proper counseling was done to the guardians of minor and all the adult patients about the procedure and written informed consent was taken accordingly. All patients were operated under cardio-pulmonary bypass (CPB) following a standard protocol through mid-sternotomy, systemic heparinization, antegrade intermittent cold cardioplegic arrest of the heart. After weaning from CPB protamine was administered to neutralize the action of heparin. A pre-operative hemoglobin $(\mathrm{Hb})$ and hematocrit (Hct) measured just before systemic heparinization. One bag of blood drawn from the patient's body when the $\mathrm{Hb}$ and $\mathrm{Hct}$ more. Meticulous hemostasis done after weaning from cardio-pulmonary bypass. Both systemic and local tranexamic acid plus calcium injection was given before sternal wires are tighten. All the blood in the cardio-pulmonary bypass machine was returned at the end of operation. Patient's hemoglobin and hematocrit checked to detect the need for transfusion. All other variables were studied. Results: Ten patients were operated without pre-operative blood transfusion of donor blood. Out of ten patients male $=5$ female $=5$, Male:Female $=1: 1$ age range $5-26$ years mean \pm SD (13 \pm-6.88$)$ years. Preop diagnosis ASD $4 / 10=40 \%$,VSD $3 / 10=30 \%$ TOF $2 / 10=20 \%$ AVR $=1 / 10=10 \%$. pre-operative Hb Range: $12.4-17.3 \mathrm{gm} / \mathrm{dl}$. Mean \pm SD (14.25 \pm-1.66 gm/dl. Pre-operative Hct mean \pm SD (43.7 \pm 4.5$)$. Per-operative Hct during CPB Mean \pm SD (24.9 \pm 4$)$. Post-operative $\mathrm{Hb}$ mean \pm SD $(11.25 \mathrm{gm} \pm 1.18 \mathrm{gm})$. Post-operative Hct mean $\pm \mathrm{SD}$ (34.3 \pm 3.80$)$. Use of cell saver 1/8(12.5\%) Post-operative blood loss for ASD,VSD, TOF and AVR were mean $\pm \mathrm{SD}=140 \pm 20.60 \mathrm{ml}, 156.44 \pm 33.84 .320 .80 \pm 60.22 \mathrm{ml}$ and $280 \mathrm{ml}$ respectively. Varieties of ionotropes used were: Dopamine Dobutamin Adrenaline. Single ionotrope Dopa/Dobuta $5 / 10=50 \%$ Double ionotrope Dopa/dobuta+Adrin $=3 / 10(30 \%)$ tripple ionotrope $2 / 10(20 \%)$. Morbidity and mortality $0 \%$. All the patients were discharged home uneventfully, in hospital outcome was good. Conclusion: In our setup we can do cardiac surgery without pre-operative donor blood use by following blood pre-donation and other blood conservative techniques.] [Journal of National Institute of Neurosciences Bangladesh, 2019;5(1): 53-58]
\end{abstract}

Keywords: Cardiac surgery; Donor blood transfusion; Bangladesh

Correspondence: Dr. Kazi Shariful Islam, Associate Professor, Department of Cardiac Surgery, National Institute of Cardiovascular Diseases, Sher-E-Bangla Nagar, Dhaka-1207, Bangladesh; Cell No.: +8801711370745; Email: kazishariful_islam@yahoo.com Conflict of interest: I do not have any conflict of interest with any one.

Funding agency: This research project was not funded by any group or any institution.

Contribution to authors: Islam KS, Sabur SAMAhave contributed from the protocol preparation, data collection up to report writing. Manuscript writing was performed by Hasan KA, Chowdhury BMM.Statistical analysis was performed by Islam KS. Yasmin N, Zahid M. have involved in revision of manuscript.

How to cite this article: Islam KS, Sabur SAMA,Hasan KA, Chowdhury BMM, Yasmin N, Zahid M. Cardiac Surgery without Donar Blood Transfusion at Referral Cardiac Institute in Bangladesh: A Single Centre Experience. J Natl Inst Neurosci Bangladesh 2019;5(1): 53-58

Copyright: (C2019. Islam et al. Published by Journal of National Institute of Neurosciences Bangladesh. This article is published under the Creative Commons CC BY-NC License (https://creativecommons.org/licenses/by-nc/4.0/). This license permits use, distribution and reproduction in any medium, provided the original work is properly cited, and is not used for commercial purposes. 


\section{Introduction}

Open heart surgery is done on various structures of the heart and great vessels with the help of Heart-Lung machine. This machine takes over the pumping action of the heart and gas exchange function of the lungs. Another machine is used to control the patient's body temperature during surgery called Heater-cooler machine. After establishment of cardiopulmonary bypass and lowering the body temperature cross clamp is applied on the proximal aorta. Heart is arrested by giving antegrade intermittent cold blood cardioplegic solution through an aortic root cannula ${ }^{1}$.

During cardiac surgery before cannulation of the heart and great vessels systemic heparinization is done with 300 to $400 \mathrm{u} / \mathrm{kg}$ to achieve a desired activated clotting time (ACT) $\geq 480 \mathrm{sec}$. By using formula desired amount of crystalloid solutions, usually Ringer's lactate solution with other additives are added to the cardiopulmonary bypass circuit. This causes a drop in the hematocrit level of the patient upto a desired level when circulated through patients body ${ }^{2}$. Hemodilution may be mild, moderate or severe if the hematocrit is $>25 \%, 21$ to $25 \%$ and $<21 \%$ respectively. Severe hemodilution during CPB is associated with post-operative renal failure which may need dialysis and cerebral stroke ${ }^{3-4}$. With this technique all types of open-heart surgery are done here.

Blood transfusion in the perioperative period of cardiac surgery is a common practice here and other cardiac surgery centres of this country. Minimum 01, upto 08 units or more of blood and blood product like FFP are required. Sometimes few extra units of blood for those post cardiac surgery patients who bleed too much in the post-operative period.

Donor allogenic blood transfusion always carry some risk. Blood transfusion-associated hazards are Transfusion-associated circulatory overload. Transfusion related acute lung injury, Haemolytic transfusion reactions and alloimmunization. Acute transfusion reactions, Non-haemolytic febrile transfusion reactions, Allergic transfusion reactions, Combined features of both febrile and allergic reactions, Hypotensive reactions, Transfusion-associated dyspnoea, Post-transfusion purpura, Transfusion-associated graft vs host disease, Transfusion-related iron overload (haemosiderosis) and Transfusion transmitted infection (TTI). Bacterial contamination, Platelets have the highest risk of bacterial contamination (1:2000) because they are stored at room temperature; the risk with red cell concentrates is much lower at 1:500 000. Risk of viral infection Hepatitis B 1:450 000 Hepatitis C 1:32 000000 HIV 1:5000 000 Human T cell leukaemia virus 1 1:12 500 00.Variant
Creutzfeld Jacob disease. Complications of massive transfusion like Hypothermia, Coagulopathy, Acid base disturbance Electrolyte abnormalities and so one ${ }^{2}$. If this donor blood transfusion can be avoided during the perioperative period it will help the patient from transfusion related hazards

Autologous pre-donation means when some patient deposits one or more units of his own blood for autologous blood transfusion before an anticipated need like elective surgery ${ }^{5}$.

The main objective of this study was to show the varieties of cardiac surgery can be done without donor blood transfusion and without any significant morbidity and mortality. So far this sort of transfusion strategy in cardiac surgery is being done infrequently in this centre and other centres of Bangladesh.

\section{Methodology}

This was a retrospective study carried out at tertiary referral cardiac Institute named National Institute of Cardiovascular Diseases, Dhaka, Bangladesh in Bangladesh from 2003 to 2013.Patients were selected purposively and conveniently. From every patient preoperative proper counseling was done to the guardians of minor and all the adult patients about the procedure and written informed consent was taken accordingly. All patients were operated under cardiopulmonary bypass (CPB)following a standard protocol through mid-sternotomy, systemic heparinization, antegrade intermittent cold cardioplegic arrest of the heart. After weaning from Cardio-pulmonary-Bypass,injection protamine sulphate was administered to neutralize the action of heparin. A preoperative hemoglobin and hematocrit with Arterial Blood Gas and Serum Electrolyte was checked. Just before systemic heparinization. One bag of blood was drawn from the patient's body when the hemoglobin and hematocrit value was higher.Sometimes this pre-donation is done in the blood bank in the morning or days before surgery. Meticulous hemostasis was done after weaning from cardiopulmonary bypass. Both systemic and local tranexamic acid+calcium injection was given before sternal wires are tighten. Cell saver machine was used to collect the shed blood into the vacuum sucker. Before administration of the injection protamine sulphate all the blood in the cardio pulmonary bypass circuit was returned to the body after vasodilatation with sodium nitroprusside and diuresis. Arterial Blood Gas and serum electrolytes including hemoglobin and hematocrit were checked in operation theatre and Intensive Care Unit till they reached at 
satisfactory level. Blood transfusion was given if hemoglobin level was less than $8 \mathrm{~g} / \mathrm{dl}$. and hematocrit was less than $26 \%$. Patient's hemodynamic status, clinical state, morbidity and mortality were recorded.

\section{Results}

The age of the patients were minimum 5years and maximum 26 years withMean \pm SD $(13 \pm 6.88)$ with male female ratio 1:1 (Table 1).

Table 1: Demographic variables

\begin{tabular}{lc}
\hline Variable & Mean \pm SD \\
\hline Age & $13 \pm 6.88($ Range $5-26$ years $)$ \\
Sex & $\mathrm{M}: \mathrm{F}=1: 1$ \\
\hline
\end{tabular}

$\mathrm{SD}=$ Standard deviation; $\mathrm{M}=$ Male; $\mathrm{F}=$ female

Forty percent patients of this series of patients pre-donated before surgery. In seventy-five percent cases predonated blood was collected in the operation theatre from CVP line in a blood bag. twenty-five percent cases it was in the blood bank (Table 2).

Table 2: Pre-donation status

\begin{tabular}{|c|c|c|}
\hline Variables & Frequency & Percent \\
\hline Predonation & $4 / 10$ & 40 \\
\hline $\begin{array}{l}\text { Return of CPB circuit } \\
\text { blood to the body after } \\
\text { weaning from CPB }\end{array}$ & $10 / 10$ & 100 \\
\hline Cell saver machine Use & $2 / 10$ & 20 \\
\hline Inj. Tranexamic acid + Ir & ium & \\
\hline $\begin{array}{l}\text { I/V Systemic+Local } \\
\text { in the mediastinum }\end{array}$ & $3 / 10$ & 30 \\
\hline Systemic IV & $6 / 10$ & 60 \\
\hline None & $1 / 10$ & 10 \\
\hline
\end{tabular}

*CPB=Cardiopulmonary bypass; IV=Intravenous; BB=Blood bank; OT=Operation Theatre

Those patients underwent cardiac surgery in this protocol, were ASD (40\%). VSD (30\%), TOF (20\%), AVR(10\%) (Table 3).

Table 3: Preoperative Diagnosis

\begin{tabular}{lcc}
\hline Preoperative.Diagnosis & Frequency & Percentage (\%) \\
\hline ASD & 4 & 40 \\
VSD & 3 & 30 \\
TOF & 2 & 20 \\
AVR & 1 & 10
\end{tabular}

*ASD=Atrial Septal Defect VSD=Ventricular Septal Defect; $\mathrm{TOF}=$ Tetralogy of Fallot AVR=Aortic Valve replacement

The mean hemoglobin values in preoperative, peroperative and postoperative periods were Mean $\pm \mathrm{SD}=14.25 \pm 1.66,8.33 \pm 11.25 \pm 1.18$ respectively (Table 4).

Table4: Perioerative Hemoglobin(HB) and Hematocrit(HCT)

\begin{tabular}{lcccc}
\hline Variables & \multicolumn{2}{c}{ HB(Gm/DL) } & \multicolumn{2}{c}{ HCT(\%) } \\
\hline & Range & Mean \pm SD & Range & Mean \pm SD \\
Preoperative & 12.4 to 17.3 & $14.25 \pm 1.66$ & 36 to 54 & $43.7 \pm-4.5$ \\
Peroperative & 7.6 to 9.60 & $8.33 \pm 1.33$ & 22 to 30 & $24.9 \pm 4.0$ \\
Postoperative & 9.8 to 12.43 & $11.25 \pm 1.18$ & 30.4 to 40 & $34.3 \pm 3.80$ \\
\hline
\end{tabular}

*; ASD=Atrial Septal defect; VSD=Ventricular septal defect; TOF=Tetralogy of Fallot; AVR=Aortic Valve Replacement

Different blood conservation techniques were adopted they were: Pre-donation(40\%),Return of CPB circuit maximum amount of blood(100\%), Use of cell saver(20\%), Systemic and local use of inj tranexamic acid( $30 \%)$, only systemic $(60 \%)$ and none in $10 \%$ cases (Table 5).

Table 5: Blood ConservationTechnique Adopted

\begin{tabular}{lcc}
\hline Variables & Number of patients & Percentage $(\%)$ \\
\hline Predonation & $04 / 10$ & $\mathbf{4 0}$ \\
Site of predonation & & \\
In the blood bank & $1 / 4$ & $\mathbf{2 5}$ \\
In the OT & $3 / 4$ & $\mathbf{7 5}$ \\
\hline
\end{tabular}

In $40 \%$ cases single ionotrope, $30 \%$ cases double ionotrope and in another $30 \%$ cases triple ionotropes were used together with vasodilator GTN.Duration of inotropes also varied depending on the number of ionotrope used like: Mean $\pm \mathrm{SD}=1.80 \pm 0.20,2.2 \pm 0.24$ and $4.6 \pm 1.02$ days for single double and triple ionotropes (Table 6).

Table 6: Ionotropes and vasodilator(GTN) used and Their duration of use

\begin{tabular}{lccc}
\hline $\begin{array}{l}\text { Ionotropes and } \\
\text { vasodilator }\end{array}$ & Frequency & Percent & $\begin{array}{c}\text { Duration(Days) } \\
\text { Mean } \pm \text { SD }\end{array}$ \\
\hline $\begin{array}{l}\text { Dopamine+GTN } \\
\text { Dobutamune+ }\end{array}$ & 4 & 40.0 & $1.80 \pm 0.20$ \\
Adrenaline+GTN & 3 & 30.0 & $2.2 \pm 0.24$ \\
$\begin{array}{l}\text { Dopamine+Dobutamine+ } \\
\text { Adrenaline+GTN }\end{array}$ & 3 & 30.0 & $4.6 \pm 1.02$ \\
\hline
\end{tabular}

GTN=Glyceryl Trinitrate, $\mathrm{SD}=$ Standard Deviation

Outcome variables were studied like Aortic cross clamp time which varied according to the type of the procedure with the lowest in ASD $(18.08 \pm 2.26) \mathrm{min}$ and highest in AVR (80min).VSD (20.34 \pm 0.24$) \mathrm{min}$,

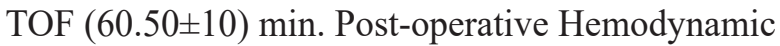


Table 7: Outcome Variables

\begin{tabular}{lcccc}
\hline Name of Variables & ASD(N=4) & VSD(N=3) & TOF(N=2) & AVR(N=1) \\
\hline XCT ( min) & $18.08 \pm 2.26$ & $20.34 \pm 0.24$ & $60.50 \pm 10$ & 80 \\
ECCT (min) & $22.50 \pm 2.78$ & $25.02 \pm 0.30$ & $75.76 \pm 12.25$ & 100 \\
Post-operative Hemodynamic status of the patients & Stable & Stable & Stable & Stable \\
Post OP Blood loss (ml)Mean \pm SD & $140 \pm 20.60$ & $156.44 \pm 33.84$ & $320.80 \pm 60.22$ & 280 \\
ICU Stay(days) & $2.8 \pm 1,02$ & $3.2 \pm 1.26$ & $5.6 \pm 1.30$ & 4.60 \\
Hospital Stay(days) & $7.2 \pm 1.04$ & $8.02 \pm 0.92$ & $10.40 \pm 1.02$ & 9.00 \\
Morbidity & None & None & None & None \\
Mortality & None & None & None & None \\
\hline
\end{tabular}

*ASD=Atrial Septal defect; VSD=Ventricular Septal Defect;TOF=Tetralogy of Fallot;

$\mathrm{AVR}=$ Aortic Valve Replacement

status of the patients were stable in all cases. Postoperative blood loss (ml) Mean $\pm \mathrm{SD}=140 \pm 20.60$, $156.44 \pm 33.84,156.44 \pm 33.84,320.80 \pm 60.22$ and $280 \mathrm{ml}$ for ASD VSD,TOF and AVR respectively.ICU stay and hospital stay varied according to type of surgery with lower in ASD, VSD(ICU-2.8,3.2, Hospital-7.2,8.02) days and higher in TOF and AVR(ICU-5.6 and4.6,Hospital-10.40,9) days. There were no morbidity and mortality of the above patients in the hospital (Table7).

\section{Discussion}

Documented only ten patients were operated over 10 years'period. Because it is a challenging surgery to be done by the cardiac surgeons. That is why these cases are performed very infrequently in this institute. As aresult, the number of cases is small.

Open heart surgical procedures without donor blood transfusion were done sporadically over that period. Both adult and paediatric patients were operated. Congenital and valve surgery were done with dominating congenital heart surgery. This sort of procedure was challenging for surgeons, perfusionists, anaesthesiologists and other members of the surgical team of a developing cardiac surgery centre.

Regarding transfusion of blood there are two strategies followed. One is restrictive, where blood transfusion is given when $\mathrm{Hb}$ is $\leq 7-8 \mathrm{gm} / \mathrm{dl}$ and the other is liberal if the hemoglobin is $\leq 9 \mathrm{gm} / \mathrm{dl}^{6-11}$. This centreis practicing liberal strategy of blood transfusion in the perioperative period.

Adult and pediatric intensive care unit patients, transfusion should be considered at hemoglobin concentrations of $7 \mathrm{~g} / \mathrm{dL}$ or less. In postoperative surgical patients, transfusion should be considered at a hemoglobin concentration of $8 \mathrm{~g} / \mathrm{dL}$ or less or for symptoms like chest pain, orthostatic hypotension or tachycardia unresponsive to fluid resuscitation, or congestive heart failure ${ }^{6-11}$.

Jehovas witness people donot receive others blood due to their religious faith. A large cohort of patients of this belief was studied who did not receive transfusion rather some alternative blood conservation techniques were applied. The outcome was comparable to those of low risk cardiac surgery patients. From this sort of operative procedures some centres tried on non-Jehovas witness patients. They proved that it was feasible and some centres are regularly practicing cardiac surgery like them ${ }^{12-14}$.

Pre-donation was done in two TOF patients in this centre because their hemoglobin and hematocrit levels were very high in relation to acyanotic patients and also in two other patients despite low normal hemoglobin level. Allogeneic blood transfusion rate was $13 \%$ in patients with pre-donation versus $48.0 \%$ without pre-donation $(\mathrm{p}<0.05)$. This difference remained statistically significant even after risk stratification $^{10}$.

In a study it has been shown that the pre-donation of 1 , 2 or 3 units of blood reduced the probability of receiving allogeneic blood to $24 \%, 14.0 \%$ and $9 \%$ respectively. An efficient program of pre-donation within the department of anesthesiology allowed keeping the costs of pre-donation low. Decision-tree analysis revealed that pre-donation of 2 autologous units of blood saved the most allogeneic blood for the smallest increase in costs. Incremental cost for male patients pre-donating 2 units was $\$ 33$ (US), whereas for females pre-donation could be done at no extra cost in comparison to patients without pre-donation. Autologous blood donation significantly reduces allogeneic blood requirement in cardiac surgery. If adjusted for diagnosis and gender, autologous blood donation is a cost-effective alternative to reduce 
allogeneic blood consumption ${ }^{10}$.

A case report published on the website of MYO Clinic USA in 2017 regarding performing an open-heart surgery in a little girl without donor blood transfusion.Preoperatively they used erythropoietin and iron supplements to raise her hemoglobin level upto 15-16 gm. During surgery crystalloid solution was used to prime the reservoir of oxygenator. Perfusionists also shortened the tubings of the circuit to use minimum prime volume. Her post-operative hemoglobin was $12 \mathrm{gm} / \mathrm{dl}$. The outcome was successfu $1^{15}$. This is a good example of protocol to be followed to avoid transfusion during cardiac surgery.

In this centre few cases over 10 years' time were done and it was known about Jehova's witness people's reservation regarding receiving blood transfusion. Cardiac surgeons of this centre took some valiant steps to do such operations in a selected group of patients here. One patient could not arrange blood before operation, but he needed surgery. He was given alternative option of pre-donation, then he gave consent and his operation was done with successful outcome. That inspired the surgeons to do few more cases. The result of this procedure in this centre on limited number of patients and international data on this issue show that it is possible to do such operations without donor blood transfusion.

There is some limitation of this study. It is a retrospective study with small number of cases. Different surgeons of the same institute did operation without preoperative injection erythropoietin to raise hemoglobin level. Liberal strategy for blood transfusion is usually practiced here.

\section{Conclusion}

Open heart surgery can be done safely without donor blood transfusion by the use of preoperativeinj erythropoietin, pre-donation of patient's own blood, autologous transfusion, meticuloushemostasis and other blood conservation techniques in the peri-operative period. As this local and international data support more challenges may be taken by the cardiac surgeons of this country. This study should be expanded on greater number and variety of cardiac surgery patients to strengthen the result of this study. This will definitely save blood, money and risk of transfusion-transmitted infection and hazards. As a result,the postoperative outcome of the patients will be better.

Acknowledgement: I acknowledge the contribution of the surgeons, perfusionists anaesthesiologists, nurses and other staffs of this institute who participated in the above mentioned 10 cardiac surgeries without perioperative blood transfusion.

\section{References}

1. KouchoukosN T, Blackstone E.H, Hanley FL Kirklin J.K. (Eds).Hypothermia,Circulatory arrest,and Cardiopulmonary bypass.,In Kirklin/Barratt-BoyesCardiac Surgery.4th ed .2013.Philadelphia:Elsevier Saunders:p.68-132.

2.Clevenger B, Kelleher A, Hazards of blood transfusion in adults and children.Continuing Education in Anaesthesia Critical Care \& Pain, 2014, Issue (3): p.112-118.

3. Karkouti K1, Beattie WS, Wijeysundera DN, Rao V, Chan C, Dattilo KM.et al. Hemodilution during cardiopulmonary bypass is an independent risk factor for acute renal failure in adult cardiac surgery.J Thorac Cardiovasc Surg. 2005 ;129(2):p.391-400.

4.Beattie.S.,, Ludwik F, Duminda W,Joan I, and Jacek K, Low Hematocrit During Cardiopulmonary Bypassis Associated With Increased Risk of Perioperative Stroke in Cardiac Surgery.Ann Thorac Surg 2005;80:p.1379-81.

5.Predonation. (n.d.) McGraw-Hill Concise Dictionary of Modern Medicine. 2002. Retrieved from: https://medical-dictionary. thefreedictionary.com/predonation [Accessed 2nd September 2018].

6. Jeffrey L. Carson J L, Kleinman S, Indications and hemoglobin thresholds for red blood cell transfusion in theadultAvailablefrom: https://www.uptodate.com/search?q $=$ cache $\% 3 \mathrm{Ad} 0 \mathrm{~g} 5 \mathrm{v} 2 \mathrm{kBM} 3 \mathrm{UJ}$ $\% 3$ Awww.uptodate.com $\% 2$ Fcontents $\% 2$ Findications-and-hemogl obin-thresholds-for-red-blood-cell-transfusionufion-in-the-adult $\%$ $20 \& \mathrm{~cd}=11 \& \mathrm{hl}=\mathrm{en} \& \mathrm{ct}=\mathrm{clnk} \& \mathrm{gl}=\mathrm{bd} \& \mathrm{client}=$ opera $\&$ redirect $=$ true [Accessed 12th October2018].

7. Clinical Transfusion Practice by World Health Organization Available from:

https://www.who.int/bloodsafety/transfusion_services/ClinicalTra nsfusionPracticeGuidelinesforMedicalInterns Bangladesh.pdf [Accessed on 10th October 2018].

8. Yaddanapudi S and Yaddanapudi LN Indications for blood and blood product transfusion.Indian J Anaesth.2014, 58(5): p.538-542.

9. Up to date.Indications and hemoglobin thresholds for red blood cell transfusion in the adultAvailable from: $\mathrm{https}$ ://www.uptodate.com/contents/indications-and-hemoglobin-t hresholds-for-red-blood-cell- transfusion-in-the-adult [ Accessed 5th October 2018].

10. Dietrich W1, Thuermel K, Heyde S, Busley R, Berger K. Autologous blood donation in cardiac surgery: reduction of allogeneic blood transfusion and cost-effectiveness. J Cardiothorac Vasc Anesth. 2005 ;19(5):p.589-96

11. Carson JL, Grossman B J, Fung M.K, Holcomb J B, Illoh Clinical Guideline Ann Intern Med. 2012;157:49-58

12. Health essentials Cleveland clinic.Available from https://health.clevelandclinic.org/blood-transfusions-after-open-h eart-surgery [Accessed 5th October 2018]

13. Vaislic,j C D.; Dalibon, N; Ponzio, O;, Maguette Ba; Jugan, E; Lagneau, Fk; et al. Outcomes in cardiac surgery in 500 consecutive Jehovah's Witness patients: 21 year Experience. 2012, 7:95. Available from: http://www.cardiothoracicsurgery.org/content 17/1/95 [Accessed 6th October 2018]

14. Jassar, A S, Ford, P A, Haber H L, IsidroA S, Jabaris D, BavariaJ E..et al.Bridges, 2012. Cardiac Surgery in Jehovah's Witness Patients: Ten-Year Experience TheAnnals of thoracic surgery.Availablefrom:doi:10.1016/j.athoracsur.2011.06.029.01 [ Accessed on 11.10 2018].Journal of Cardiothoracic Surgery 2012, 
7:95 Available from:://www.cardiothoracicsurgery.org/ content/7/1/95 [Accessed 7th October 2018].

15. Sharing Mayo Clinic. Open-Heart Surgery Achieves Success Without Blood Transfusions by SharingMayoClinic October 26,
2017 Available from:https://sharing.mayoclinic.org/2017/10/26/ open-heart-surgery-achieves-success-without-blood-transfusions / [Accessed 2nd October.2018]. 